\title{
LA EFICACIA ENTRE PARTICULARES DE LA CARTA DE DERECHOS FUNDAMENTALES DE LA UNIÓN EUROPEA A LA LUZ DE LA JURISPRUDENCIA DEL TRIBUNAL DE JUSTICIA
}

\author{
JUAN IGNACIO UGARTEMENDIA ECEIZABARRENA \\ Catedrático Jean Monnet \\ Catedrático $(A)$ de Derecho Constitucional \\ Universidad del País Vasco ${ }^{1}$
}

SUMARIO

I. Introducción: panorámica general de los sujetos vinculados por la Carta. II. La eficacia vinculante de la CDFUE entre particulares. III. Margen de actuación del Juez nacional en la tutela (inter privatos) de los Derechos Fundamentales en el ámbito de aplicación del Derecho de la Unión Europea.

\section{INTRODUCCIÓN: PANORÁMICA GENERAL DE LOS SUJETOS VINCULADOS POR LA CARTA}

¿Quiénes son los sujetos obligados a respetar la Carta de Derechos Fundamentales de la Unión Europea (CDFUE)? Y más en concreto, ¿están los particulares vinculados por la misma?

La respuesta inicial viene establecida en el art. 51.1 de la propia Carta, cuando señala que «las disposiciones de la presente Carta están dirigidas a las instituciones, órganos y organismos de la Unión, dentro del respeto del principio de subsidiariedad, así como a los Estados miembros únicamente cuando apliquen el Derecho de la Unión (...)». Como cabe observar, la disposición alude a la sujeción que desarrolla la Carta frente al poder público — sea de la Unión o de los Estados miembros—, esto es, a

1 Este trabajo ha sido realizado en el marco del Proyecto de Investigación GIC IT675-13 y de la UFI 11/05, dedicados al estudio de la integración política y económica europea, así como de la Cátedra Jean Monnet de la UPV/EHU (Programa ERASMUS + de la Unión Europea, Ref.: 553187-EPP-1-2014-1-ES-EPPJMOCHAIR). 
la eficacia vertical. Pero nada se dice, sin embargo, sobre la eficacia «horizontal»o inter privatos, es decir, la que se desarrollaría en las relaciones entre particulares (también conocida como Drittwirkung).

En todo caso, parece evidente que la mencionada disposición, con ser básica y fundamental (y que aparece «completada» por las «Explicaciones» a la Carta que deberán ser tenidas en cuenta por los órganos jurisdiccionales de la Unión y de los Estados miembros al interpretar la Carta), no deja de ser genérica y un tanto abierta, suscitando innumerables dudas y cuestiones, a las cuales va respondiendo el Tribunal de Justicia de la Unión (TJ). En lo que sigue apuntaremos brevísimamente los principales datos referidos a aquella eficacia vertical, para centrarnos a continuación en la desplegada en las relaciones entre particulares, utilizando para ello la perspectiva de la jurisprudencia del TJ así como las Conclusiones de los Abogados Generales.

a) La eficacia (vertical) frente a los actos de la Unión: Tal y como se ha señalado, los primeros entes que se mencionan como vinculados por la Carta son las instituciones, órganos y organismos de la Unión. El Tribunal competente para controlar dicho respeto es el Tribunal de Justicia, quien puede declarar nulos los actos contrarios, incluso los actos legislativos (piénsese, por ejemplo, en la STJ Digital Rights Ireland ${ }^{2}$, en la que controla y declara inválida la Directiva 2006/24/CE sobre la conservación de datos electrónicos, por ser contraria a los arts. 7 y 8 de la Carta) ${ }^{3}$. Por su parte, el órgano judicial nacional, si bien no puede realizar el control, sí puede ayudar a activarlo vía cuestión prejudicial.

Aunque hay que entender que «cualquier» autoridad pública de la Unión (y por lo tanto, también las Agencias) está vinculada por la Carta, surge alguna incertidumbre, sin embargo, acerca de la intensidad de esa sujeción en algunos supuestos concretos. Este sería el caso, por ejemplo, en relación a los actos en el ámbito de la PESC (Política Exterior y de Seguridad Común). Y ello porque, aun cuando todos los actos de la Unión están sometidos a la Carta, el Tribunal de Justicia —según el art. 275.1 TFUE - sigue careciendo de competencias para controlar las disposiciones y actos relativos a la PESC (salvo excepciones, como la de pronunciarse sobre los recursos interpuestos por las personas físicas o jurídicas contra «medidas restrictivas» que les afecten). De manera que, cabe pensar, sin posibilidad de control jurisdiccional parece que se difumina o diluye la relación de sujeción con respecto a la Carta, o al menos su intensidad.

2 De 8 de abril de 2014, C-293/12.

3 Al respecto, por ejemplo, D. Marinas SuÁreZ, El control iusfundamental de los actos legislativos de la Unión Europea. Una aproximación desde el Tribunal de Justicia de la Unión Europea, Thomson Reuters-Aranzadi, Cizur Menor, 2015. 
Otro caso problemático es el que surge en la medida que existen actuaciones de instituciones u órganos de la Unión que caen, aunque parezca extraño, fuera del Derecho de la Unión. Pensemos, por ejemplo, en la decisión de los Estados miembros de crear el Mecanismo Europeo de Estabilidad (MEDE) mediante un acuerdo internacional al margen del ámbito de la Unión ${ }^{4}$ (o en el llamado «Pacto fiscal europeo» ${ }^{5}$ ) y en las actuaciones de instituciones de la Unión (Comisión Europea o el Banco Central Europeo), previstas en un Tratado de ese tipo, ajeno al Derecho de la Unión ${ }^{6}$. La duda reside entonces en colegir si esas actuaciones de las instituciones de la Unión al amparo y la previsión de un acuerdo internacional de este tipo, que es stricto sensu ajeno al Derecho de la Unión, son actuaciones no jurídicamente constreñidas por la CDFUE. La incertidumbre se ha despejado con la reciente STJ Ledra Advertising Ltd , en la que se declara que «si bien los Estados miembros no aplican el Derecho de la Unión en el marco del Tratado MEDE, de modo que la Carta no está destinada a ellos en dicho ámbito (...), en cambio, la Carta está dirigida a las instituciones de la Unión también cuando actúen fuera del marco jurídico de la Unión, como indicó el Abogado General en el punto 85 de sus conclusiones ${ }^{8}$.

b) La eficacia (vertical) frente a los Estados miembros: la Carta establece que, además de la Unión, también están sujetos u obligados a respetar la Carta los Estados miembros. Ahora bien, según el art. 51 de la Carta, ésta vincula a los «Estados miembros únicamente cuando apliquen el Derecho de la Unión». Esta idea central contiene, al menos, dos cuestiones importantes: por una parte, señalar qué significa o engloba aquí la expresión «Estados miembros»; y por otra, la necesidad de distinguir cuándo el Estado miembro está o no «aplicando el Derecho de la Unión». Respecto a lo primero, hay que constatar que la Carta «se aplica tanto a las autoridades

4 Tratado Constitutivo del Mecanismo Europeo de Estabilidad (firmado por los Estados miembros de la Eurozona el 2 de febrero de 2012).

5 Tratado de Estabilidad, Coordinación y Gobernanza en la Unión Económica y Monetaria (firmado el 2 de marzo de 2012 por todos los países de la Unión, salvo el Reino Unido y la República Checa).

6 «Hay que observar que los Estados miembros no aplican el Derecho de la Unión, en el sentido del artículo 51, apartado 1, de la Carta, al instituir un mecanismo de estabilidad como el MEDE, para cuyo establecimiento los Tratados UE y TFUE no atribuyen ninguna competencia específica a la Unión, según resulta del apartado 105 de la presente sentencia» (STJ PRINGLE, de 27 de noviembre de 2012, C-370/12, apdo. 180).

7 De 20 de septiembre de 2016, as. ac. C-8/15 a 10/15.

8 Apartado 67. Véase, sobre la Sentencia: D. SARmiento, «The Price of Borrowing EU Institutions, and the Price of Being Borrowed-A short comment on Ledra Advertising», en su Blog: Despite our Differences (21 de septiembre de 2016): https://despiteourdifferencesblog.wordpress.com/; in extenso en P. ANDRÉS SÁEnZ de SANTA MARÍA, «Derechos Fundamentales y gobernanza económica: ¿qué podemos esperar de la Carta?», de próxima publicación en R. Alonso García y J.I. Ugartemendia Eceizabarrena, La aplicación judicial de la Carta de Derechos Fundamentales de la Unión Europea, IVAP (European Inklings), Oñate, 2017. 
centrales como a las instancias regionales o locales así como a los organismos públicos cuando aplican el Derecho de la Unión» ${ }^{9}$.

La segunda cuestión clave es identificar qué significa la expresión «aplicar Derecho de la Unión», pues el Estado estará vinculado o sujeto a la Carta sólo cuando esté haciéndolo. Así, pues, el problema es identificar qué actuación nacional o interna entra y cuál no en esa expresión de «aplicar Derecho de la Unión». Simplificando ahora el tema, podemos decir que las diversas formas de entender la cuestión pueden reconducirse a dos: Por una parte, la que entiende la «aplicación» estatal del Derecho de la Unión en términos estrictos, no yendo mucho más allá de lo que es la situación de mera y directa ejecución de una norma europea (por ejemplo, cuando se aplica un Reglamento). Se trata, en suma, de una situación en la que el Estado actúa como mero «agente» de la Unión ${ }^{10}$. Y por otra parte, tendríamos la posición de quienes abren o extienden el concepto de aplicación nacional del Derecho de la Unión a otras actuaciones en cumplimiento de obligaciones de la Unión, además de los actos de mera ejecución. El debate al respecto es complejo, y depende también de la casuística, pero puede subrayarse que la jurisprudencia del Tribunal de Justicia ha venido asumiendo una concepción amplia o extensiva del ámbito de aplicación del Derecho de la Unión. Ello ha sido así tanto antes de que la Carta entrara en vigor (2009), cuando los DF eran reconocidos y tutelados con el formato de Principios Generales del Derecho Comunitario (y de la Unión), como ahora que rigen tanto la Carta como los principios (tras la entrada en vigor del reformado art. 6 del TUE) ${ }^{11}$.

9 Párrafo segundo de las Explicaciones relativas al artículo 51 de la Carta. A ello habría que añadir que vincula a cualquier ente público, aun cuando éste participe en una relación jurídica regida por normas de Derecho privado. E incluso cabría agregar que vincula, asimismo, a un sujeto privado, en la medida que éste actúe ostentando un privilegio o poder conferido por el Estado o valiéndose de las facultades o ventajas añadidas por éste (pensemos en posibles ejemplos como: concesionarios de servicios públicos, concesionarios de dominio público, beneficiarios de subvenciones públicas, etc.). Tomo la idea y los ejemplos del razonado análisis que hace L.M. DíEz Picazo al referirse a la eficacia de los derechos fundamentales en las relaciones entre particulares, análisis de la teoría y de su juego en el ordenamiento español (Sistema de Derechos Fundamentales, Thomson-Civitas, Madrid, 2013 (4. ${ }^{\mathrm{a}}$ ed.), pp. 143 y ss.).

10 «Agency situation», en expresión de J.H.H. WEILER, The Constitution of Europe, Cambridge University Press, Cambridge, 1999, pp. 120 y ss.

11 Por poner algunos ejemplos: STJ de 19 de enero de 2010, as. KÜCÜKDEVECI, C-555/07, apartados 22 y ss.; STJ de 23 de noviembre de 2010, as. TSAKOURIDIS, C-145/09, apartados 50-52. O en la STJ de 26 de febrero de 2013, as. AKERBERG, C-617/10, apartados 17 y ss., sobre la que volveremos más tarde. Véanse igualmente, en este sentido, por ejemplo, las Conclusiones de la Abogada General E. Sharpston, de 30 de septiembre de 2010, as. RUIZ ZAMBRANO, C-34/09, apartados 156 y ss.; o del Abogado General Yves Bot, de 5 de abril de 2011, en el as. Ivana Scattolon, C-108/10, apartados 110 y ss. A juicio de este último, la referencia del art. 51.1 a la expresión «aplicar» el Derecho de la Unión debe interpretarse, a la luz de las Explicaciones de la Carta al respecto, en el sentido de que las disposiciones de la misma se dirigen a los Estados miembros «cuando éstos actúan dentro del ámbito de aplicación del Derecho de la Unión» (apdo. 119). Para una visión doctrinal al respecto, ex plurimis, entre otros: A. EGGER, «EU-Fundamental Rights in the National Legal Order: The Obligations of Member States Revisited», Yearbook of European Law, 25, 2006, 
Pero, ¿en qué casos se detecta esa posición o interpretación amplia? O ¿cuáles son esos supuestos-tipo que el Tribunal de Justicia ha incluido como casos de aplicación estatal del Derecho de la Unión y sujetos a los DFUE (aunque no son de mera ejecución)? Haciendo una relación muy simplificada, es posible destacar, como el primero de ellos, el que surgió cuando el Tribunal estableció que los DFUE deben ser respetados no sólo cuando se ejecuta Derecho de la Unión, sino también cuando lo que los Estados hacen es «derogarlo» o «excepcionarlo» conforme a lo establecido o permitido al respecto por el mismo (por ejemplo, en atención a motivos de orden público, seguridad y salud públicas $)^{12}$.

Un segundo supuesto es el que se detecta cuando el Tribunal considera «aplicación» del Derecho de la Unión no ya la implementación de una directiva (por ej. mediante una ley), sino también, cuando las administraciones públicas nacionales aplican la Ley de transposición de la misma, y/o todas las situaciones en las que una normativa nacional «abarca» o «afecta» a una materia regida por una directiva cuyo plazo de transposición haya vencido ${ }^{13}$. Otro supuesto consiste en que la interpretación que realice el poder público nacional al cumplir con la obligación de interpretar el Derecho nacional conforme al Derecho de la Unión debe ser acorde con los DFUE ${ }^{14}$.

Y también estaría englobada la actividad estatal que aparece respondiendo a cualquier otra obligación impuesta por el Derecho de la Unión, como, por ejemplo, cuando el Estado sanciona la infracción de la Directiva 2006/112/CE (relativa al sistema común del IVA), dando cumplimiento así a la obligación impuesta por el TFUE (art. 325) a los Estados miembros de sancionar de modo efectivo los actos que causen un perjuicio a los intereses financieros de la UE. De manera que la aplicación de esas disposiciones sancionadoras en el caso concreto debe respetar la CDFUE (en este supuesto, el non bis in idem del art. 50) ${ }^{15}$.

pp. 515 y ss.; J. Kokott у Ch. Sовотта, The Charter of Fundamental Rights of the European Union after Lisbon, EU Working Papers, AEL 6/2010; A. vON BogDANDY et alii, «Cómo proteger los derechos fundamentales europeos frente a los Estados miembros», en A. von Bogdandy, J.I. Ugartemendia, A. Saiz Arnaiz y M. Morales (Coords.), La tutela jurisdiccional de los derechos. Del constitucionalismo bistórico al constitucionalismo de la integración, IVAP, Oñate, 2012, espec. pp. 145 y ss.; K. LENAERTS y J.A. GutiérReZ-Fons, «The Charter in the EU Constitucional Edifice», en S. Peers, T. Hervey, J. Kenner y A. Ward (Eds.), The EU Charter of Fundamental Rights. A Commentary, CH Beck-Hart-Nomos, Oxford and Portland, 2014, pp. 1567-1568; y D. SArmiento, El Derecho de la Unión Europea, Marcial Pons, Madrid, 2016, pp. 191-192.

12 Véanse las clásicas SSTJUE: ERT, de 18 de junio de 1991, C-260/89; FAMILIAPRESS, de 26 de mayo de 1997, C-368/95; o SCHMIDBERGER, de 12 de junio de 2003, C-112/00, entre muchas.

13 Vid. D. Sarmiento, El Derecho de la Unión Europea, op. cit., p. 192. Véanse, por ejemplo, la ya mencionada Sentencia TSAKOURIDIS, apdos. 50 y ss.; o KÜCÜKDEVECI, cit., apdos. 22 y ss.

14 Cfr. las SSTJUE: LINDQUIST, de 6 de noviembre de 2003, C-101/01, apdo. 87; GRONGAARD, de 22 de noviembre de 2005, C-384/02, apdo. 30; de 15 de enero de 2014, AMS, C-176/12, apdo. 39; y de 13 de julio de 2016, PÖPPERL, C-187/15, apdo. 44. Véanse, asimismo, las Conclusiones del Abogado General Michal Bobek de 11 de octubre de 2016 al as. E. MILEV, C-439/16 PPU, apdo. 51.

15 SSTJUE: AKERBERG, de 26 de febrero de 2013, C-617/10; o IVO TARICCO, de 8 de septiembre de 2015, C-105/14, apdo. 50 y ss. 
Toda esta interpretación amplia del ámbito de aplicación de la Carta queda gráficamente retratada, por ejemplo, en la mencionada Sentencia Akerberg, cuando declara que «(...) no existe ningún supuesto comprendido en el Derecho de la Unión en el que no se apliquen dichos derechos fundamentales (...) ${ }^{16}$. Ahora bien, también hay que señalar que, pese a manejar esta concepción, el Tribunal tampoco deja de marcar límites a ese ámbito, señalando que la Carta rige sólo cuando existe una «conexión» suficiente con el Derecho de la Unión, o sólo cuando la situación entra en el radio (o marco o ámbito) de acción/aplicación del Derecho de la Unión ${ }^{17}$.

\section{LA EFICACIA VINCULANTE DE LA CDFUE ENTRE PARTICULARES}

\section{Las diversas posiciones acerca de la eficacia horizontal de la Carta}

El artículo 51.1 de la Carta sólo señala literalmente como destinatarios de la misma a las Instituciones de la Unión y a los Estados miembros. Este dato suscita que surjan diversas y encontradas posiciones o puntos de vista acerca de si la Carta vincula también directamente a los particulares, a los que no se menciona en la misma. Esas posiciones se pueden simplificar ahora, a efectos descriptivos, en $\operatorname{dos}^{18}$.

16 STJ Akerberg, cit., apdo. 21.

17 Cabe citar al respecto, por ej., las SSTJ: KREMZOW, de 29 de mayo de 1997 (C-299/95), apartado 15; ANNIBALDI, de 18 de diciembre de 1997(C-309/96), apartado 13; VINKOV, de 7 de junio de 2012 (C-27/11), apartado 59; la ya citada ÅKERBERG, apartado 19; y más recientemente: SIRAGUSA, de 6 de marzo de 2014 (C-206/13), apartado 24; TORRALBO MARCOS, de 27 de marzo de 2014 (C-265/13), apdos. 30 y ss.; JULIÁN HERNÁNDEZ, de 10 de julio de 2014 (C-198/13). O el Auto TJ GRODECKA, de 2 de junio de 2016 (C-50/16), apdos. 17 y ss. Sobre el tema, entre otros: R. Alonso García, El Juez Nacional en la Encrucijada Europea de los Derechos Fundamentales, Civitas, Madrid, 2014, pp. 33 y ss.; F. VALDÉs DAL-RÉ, El constitucionalismo laboral europeo y la protección multinivel de los derechos laborales fundamentales: luces y sombras, Ed. Bomarzo, Albacete, 2016, pp. 45 y ss.; o J. Huelin Martínez DE Velasco, «Las cláusulas horizontales de la Carta de Derechos Fundamentales de la Unión Europea. Dos manifestaciones de su aplicación jurisdiccional (una constitucional y otra ordinaria), en R. Alonso García y J.I. Ugartemendia Eceizabarrena, La aplicación judicial de la Carta..., op. cit., puntos 26 y ss.

18 En relación al tema de la eficacia entre particulares de los Derechos Fundamentales, entre otros muchos: J.M. Bilbao Ubillos, La eficacia de los derechos fundamentales frente a particulares. Análisis de la jurisprudencia del Tribunal Constitucional, CEPC, Madrid, 1997; A. ClaPham, Human rights in the private sphere, Clarendon Press, Oxford, 1993; C. STARCK, «Derechos fundamentales y Derecho privado», REDC, 2002, 22, pp. 65 y ss.; P. DE VEGA, «La eficacia frente a particulares de los derechos fundamentales (la problemática de la Drittwirkung der Grundrechte)», en AAVV, Constitución, Estado de las autonomías y Justicia Constitucional (libro homenaje al profesor Gumersindo Trujillo), Tirant lo Blanch, Valencia, 2005, pp. 801 y ss.; P. AlsTON (Ed.), Non-State Actors and Human Rights, Oxford University Press, Oxford, 2005; R. Sarazá Jimena, «Jueces, derechos fundamentales y relaciones entre particulares», Jueces para la Democracia, 56, 2006, pp. 41 y ss.; del mismo, La protección jurisdiccional de los derechos fundamentales en las relaciones entre particulares, Tirant lo Blanch, Valencia, 2011; J.H. KNOx, «Horizontal Human Rights Law», American Journal of International Law, 102, 2008, pp. 1 y ss.; L.M. DíEZ-PiCAZo, «Sobre la eficacia entre particulares de los derechos fundamentales», en E. García de Enterría y R. Alonso García (Coords.), Administración y justicia: un análisis jurisprudencial. 
1. Por una parte, aquella que niega esa eficacia o capacidad vinculante (directa) de los derechos de la Carta entre particulares o inter privatos, esto es, la que niega la eficacia horizontal, también llamada Drittwirkung. Para esta perspectiva los Derechos Fundamentales sólo tienen esa relevancia directa entre el Estado y el particular (eficacia vertical). Los derechos de la Carta carecen de una vigencia inmediata en el tráfico jurídico privado en el sentido de poder impedir directamente que sean válidos los negocios jurídicos que los contravengan. Según este punto de vista, esos derechos sólo vinculan entre particulares de forma mediata, a través de la legislación establecida por el Estado.

Esta es la posición mantenida, por ejemplo, por la Abogado General V. Trstenjak en sus Conclusiones en el asunto Maribel Domínguez ${ }^{19}$. Las razones básicas esgrimidas al respecto serían tres ${ }^{20}$ :

1) la mencionada omisión del art. 51.1;

2) que los particulares no están en disposición de satisfacer la reserva legal prevista en el artículo 52.1 (cuando se señala que: «Cualquier limitación del ejercicio de los derechos y libertades reconocidos por la presente Carta deberá ser establecida por la ley»), una exigencia que, por su propia naturaleza, sólo puede dirigirse a la Unión y a los Estados miembros; y

3) que tal y como demuestra el sistema del CEDH, la tutela de los Derechos fundamentales en las relaciones inter privatos no pasa necesariamente por una «vinculación directa» de los particulares a dichos derechos, bastando con que estos puedan invocar la «obligación de protección» a cargo de los poderes públicos, esto es, de las medidas protectoras que deben adoptar la Unión o los Estados miembros (las llamadas «obligaciones positivas», en terminología del TEDH).

Liber amicorum Tomás-Ramón Fernández, vol. I, Civitas-Thomson Reuters, Madrid, 2012, pp. 141 y ss.; del mismo autor, Sistema de derechos fundamentales, op. cit., pp. 140 y ss.

19 Conclusiones de 8 de septiembre de 2011, C-282/10 (vid. también sus Conclusiones presentadas el 29 de marzo de 2007 en el as. CARP, C-80/06, apdo. 60). Tal y como recuerda la Abogado General, «el problema de la «eficacia frente a terceros» trata de la cuestión de si los derechos fundamentales sólo tienen relevancia para la relación entre el particular y el Estado (es decir, si están dirigidos al Estado) o si también rigen en las relaciones entre los ciudadanos. A este respecto se defienden tanto la teoría de la «eficacia directa frente a terceros» de los derechos fundamentales como la de su «eficacia indirecta frente a terceros». Con la eficacia directa frente a terceros se hace referencia a la vigencia inmediata de los derechos fundamentales también en el tráfico jurídico privado. Según este punto de vista, por lo tanto, los negocios jurídicos no podrán contravenir los derechos fundamentales. Por el contrario, la teoría de la eficacia indirecta frente a terceros considera que las cláusulas generales constituyen «puntos de penetración» de los derechos fundamentales en el Derecho privado, y entiende que al interpretar dichas cláusulas generales se ha de tener en cuenta el sistema de valores consagrado en la legislación en materia de derechos fundamentales» (apdo. 80, as. M. DOMÍNGUEZ, nota a pie 45).

20 Apartados 80 y siguientes de las Conclusiones al señalado as. M. DOMÍNGUEZ. Al respecto, por ejemplo: D. LECZYKIEwICZ, «Horizontal Application of the Charter of Fundamental Rights», European Law Review, 38, 2013, pp. 480 y ss.; K. Lenaerts y J.A. Gutiérrez-Fons, «The Charter in the EU Constitutional Edifice», op. cit., pp. 1578-1580. 
De modo que, según esta primera posición, los particulares sólo quedan vinculados por la Carta de forma «indirecta», mediante las disposiciones del poder público que concretan la obligación de protección.

2. Ante ello, se presenta, sin embargo, la perspectiva de quien no se cierra a la eficacia directa de la Carta, si bien matizando, como veremos, las situaciones al respecto. Este sería el caso, por ejemplo, del Abogado General Pedro Cruz Villalón en las conclusiones al as. $A M S^{21}$. Los argumentos de esta parte se pueden describir, de forma simplificada, en los siguientes puntos:

1) no hay nada en el enunciado literal del art. 51.1 — ni en los trabajos preparatorios ni en las Explicaciones - que lleve a pensar que se haya querido abordar la cuestión de la eficacia de los Derechos Fundamentales de la Carta en las relaciones entre particulares (lo que se ha pretendido tratar allí es el alcance con el que estos obligan a la Unión y los Estados miembros);

2) no hay que perder de vista que la eficacia horizontal de los DF es ya una cuestión «antigua y consolidada en el Derecho de la Unión, por ejemplo, en relación a las «libertades fundamentales de circulación» ${ }^{22}$, a «determinados principios como el de no discriminación por razón de sexo» ${ }^{23}$, o a la igualdad de retribución entre trabajadores y trabajadoras para un mismo trabajo ${ }^{24}$; o respecto al derecho a adoptar medidas de conflicto

21 Conclusiones de 18 de julio de 2013, as. AMS o ASSOCIATION DE MÉDIATION SOCIALE, C-176/12, espec. apdos. 28 y ss.

22 Y cita al respecto (apdo. 34, nota a pie 6), a modo de ejemplo, las siguientes sentencias del Tribunal de Justicia: de 12 de diciembre de 1974, WALRAVE Y KOCH (36/74), en la que, recordémoslo, se declara que, el principio de no discriminación por razón de la nacionalidad de los artículos 7, 48 y 59 del Tratado CEE (artículos 18, 45.2 y 56 del TFUE, y 21.2 de la Carta DFUE), además de imponerse a la actuación de las autoridades públicas, se impone, asimismo, «a normativas de otra naturaleza [en el caso, una federación deportiva] que tengan por finalidad regular colectivamente el trabajo por cuenta ajena y las prestaciones de servicios» (apdos. 15-17). El fundamento para ello reside en que la eliminación, entre los Estados miembros, de los obstáculos a la libre circulación de personas y a la libre prestación de servicios correría peligro si la supresión de las barreras de origen estatal pudiera ser neutralizada con obstáculos derivados del ejercicio de su autonomía jurídica por asociaciones y organismos que no están sometidos al Derecho público. En idéntico sentido en las Sentencias: de 14 de julio de 1976, DONÀ (13/76), apartado 17; en la de 15 de diciembre de 1995, BOSMAN (C-415/93), apartados 82-83; de 11 de abril de 2000, DELIÈGE (C-51/96 y C-191/97), apartado 47; de 6 de junio de 2000, ANGONESE (C-281/98), apartados 31-33; de 19 de febrero de 2002, WOUTERS Y OTROS (C-309/99), apartado 120, y de 11 de diciembre de 2007, International Transport Workers' Federation y Finnish Seamen's Union, denominada «VIKING LINE»(C-438/05), apartado 33.

23 Señalando como significativa la Sentencia de 15 de junio de 1978, DEFRENNE (149/77).

24 Cabe apuntar al respecto que ya en la Sentencia DEFRENNE, de 8 de abril de 1976, 43/75 (DEFRENNE II), el Tribunal de Justicia declaró que el principio de igualdad de retribución entre trabajadores masculinos y femeninos establecido por el artículo 119 del Tratado CEE (en la actualidad artículo 157 TFUE) puede ser invocado por los justiciables ante los órganos jurisdiccionales nacionales, tanto en el caso de discriminaciones cuya causa directa sean disposiciones legislativas o convenios colectivos de trabajo, como en el supuesto de retribución desigual de trabajadores femeninos y masculinos por un mismo trabajo, cuando éste se realice en un mismo establecimiento o servicio, privado o público. Este artículo con efecto directo entre particulares dispone, en su primer apartado, que: «cada Estado miembro garantizará la aplicación del principio de igualdad 
colectivo como principio general del Derecho comunitario ${ }^{25}$. De manera que, en consecuencia, «puesto que la eficacia horizontal de los derechos fundamentales no es algo desconocido en el Derecho de la Unión, resultaría paradójico que precisamente la incorporación de la Carta al Derecho primario pudiera cambiar, para peor, este estado de cosas» ${ }^{26}$;

3) el problema de la «Drittwirkung» reside en la correcta comprensión de su eficacia en términos concretos, dado que puede adoptar manifestaciones muy variadas, viniendo «normalmente impuesta, de forma inmediata y directa, por el propio poder público» (siendo así legible, también, en términos de «deber de protección» de los derechos por parte éste; planteamiento que hizo suyo el TEDH $)^{27}$.

Unido a ello, procede recordar, tal y como ya se ha señalado con antelación, que el particular que esté ocupando o ejerciendo una posición o facultad jurídica equivalente a la propia del poder público puede, por ello mismo, verse constreñido por los DFUE de la misma forma que este mismo (sería el caso, por ejemplo, de las organizaciones sindicales, federaciones deportivas, beneficiarios de subvenciones públicas, concesionarios de servicios públicos, etc. $)^{28}$.

4) Conviene tener presente, además, que esa «proteica» eficacia horizontal de los derechos fundamentales «opera de manera muy diversa respecto de cada uno de ellos o, más sencillamente, respecto de los distintos grupos de ellos», existiendo derechos que, por su propia estructura, no se dirigen a los particulares ${ }^{29}$, del mismo modo que

de retribución entre trabajadores y trabajadoras para un mismo trabajo o para un trabajo de igual valor». El efecto horizontal vinculante se extiende no sólo a los contratos entre particulares, sino también a todos los convenios destinados a regular colectivamente el trabajo por cuenta ajena (STJUE de 9 de septiembre de 1999, KRÜGER, C-281/97, apdo. 20), o igualmente, «a los actos unilaterales de un empleador en relación con sus empleados» (STJUE de 21 de octubre de 1999, SUSANNE LEWEN, C-333/97, apdo. 26).

25 Recuérdese, por ejemplo, la STJUE $L A V A L$, de 18 de diciembre de 2007, C-341/05, donde se declara - apdo. 91- que «el derecho a adoptar medidas de conflicto colectivo es un derecho fundamental que forma parte de los principios generales del Derecho comunitario, cuyo respeto garantiza el Tribunal de Justicia, [aunque] su ejercicio puede supeditarse a ciertas restricciones» (cosa que sucede en el caso: a las organizaciones sindicales frente a la libre prestación de servicios de una empresa), y que, «como reafirma el artículo 28 de la Carta de los Derechos Fundamentales de la Unión Europea, este derecho está protegido de conformidad con el Derecho comunitario y con las legislaciones y prácticas nacionales». En idéntico sentido la ya mencionada Sentencia VIKING LINE, donde, dentro del derecho fundamental a adoptar medidas de conflicto colectivo, derecho que se entiende forma parte integrante de los principios generales del Derecho comunitario y está reconocido en el art. 28 de la Carta, se incluye expresamente el derecho de huelga (apdo. 44).

26 Apdo. 35 de las Conclusiones.

27 Apdo. 36 de las Conclusiones.

28 Cfr. D. Sarmiento, El Derecho de la Unión Europea, op. cit., p. 195.

29 Podríamos destacar, así, los principios de legalidad y de proporcionalidad de los delitos y las penas (art. 49 de la Carta); o, poniendo ejemplos entre los relativos al estatus de ciudadanía europea: el derecho a una buena administración (art. 41 de la Carta), a la protección diplomática y consular (art. 23 TFUE o 46 de la Carta) o el derecho de petición ante el Parlamento Europeo (art. 24 TFUE o 44 de la Carta). 
«hay derechos respecto de los cuales sería inconcebible negar su relevancia en las relaciones jurídico-privadas» ${ }^{30}$.

5) Finalmente, unido a lo anterior, es esencial no perder de vista la distinción entre «derechos» y «principios» recogida en los artículos 51.1 y 52 de la Carta $^{31}$, disponiéndose en este último que «las disposiciones de la presente Carta que contengan principios podrán aplicarse mediante actos legislativos y ejecutivos adoptados por las instituciones, órganos y organismos de la Unión, y por actos de los Estados miembros cuando apliquen el Derecho de la Unión, en el ejercicio de sus competencias respectivas. Sólo podrán alegarse ante un órgano jurisdiccional en lo que se refiere a la interpretación y control de la legalidad de dichos actos». Ahora bien, a este respecto, conviene advertir que la Carta no distingue los derechos de los principios como dos grupos, e incluso, en ocasiones, bajo un contenido enunciado como «derecho" puede latir un «principio». Y aunque la Carta ha englobado a todos bajo la categoría general de «derechos fundamentales» ${ }^{32}$, muchos de ellos, especialmente entre los derechos sociales, sólo funcionan o son operativos a través de la previa intermediación del poder público ${ }^{33}$. La necesidad de esa intermediación hace, obviamente, que su eficacia horizontal (como derechos) sólo pueda ser indirecta.

En suma, resulta que la Carta, además de derechos sin eficacia horizontal o entre particulares, porque no son susceptibles de tenerla, contiene otros que sí pueden desplegarla. Hay algunos que, en su caso, pueden hacerlo de forma directa, habiendo sido ello reconocido por el Tribunal de Justicia antes de que la Carta adquiriera eficacia jurídica, como ocurre con algunos derechos que regían como

30 Apdo. 38 de las Conclusiones. Pensemos, por ejemplo, en los principios a la no discriminación por razón de sexo, libertad sindical, o a adoptar medidas de conflicto colectivo.

31 Distinción introducida por la versión de la Carta del año 2007.

32 En este sentido, por ejemplo, el Abogado General Pedro Cruz Villalón recordará de forma muy clarificadora en las reiteradas Conclusiones que: «en la arquitectura de la Carta, la categoría general por la que ha optado aquélla en su propia denominación, los «derechos fundamentales», debe ser predicable en relación con todos sus contenidos. Dicho de otro modo, ningún contenido de la Carta, en sus determinaciones sustantivas, debe quedar expulsado de la categoría de «derecho fundamental». Esto sentado, conviene advertir, y esto acaso pueda parecer menos obvio, que la circunstancia de que un determinado contenido sustantivo de la Carta aparezca, en algún otro lugar de la Carta, calificado como «derecho» no lo descarta por ese solo hecho como candidato a la categoría de «principio», en el sentido del artículo 52, apartado 5» (apdo. 44). Sobre el tema, asimismo, R. Alonso García, Sistema jurídico de la Unión Europea, op. cit., pp. 393 y ss.

33 «En efecto, es frecuente, tanto en la propia Carta como en las tradiciones constitucionales de los Estados miembros, el que sean calificados como «derechos», o «derechos sociales», aquellos contenidos sustantivos de orden social que, por no poder derivarse de ellos posiciones jurídicas subjetivas inmediatamente exigibles, funcionan sólo previa la intermediación o concreción del poder público. Son «derechos» (sociales) en razón de su materia, o de su identidad incluso, y son «principios» en razón de su operatividad» (apdo. 45 de las Conclusiones en el as. $A M S$ ). 
principios generales del Derecho de la Unión (en todo caso, hay que pensar que esa eficacia sería directa en la medida en que no haya legislación —europea o nacional — que la vehicule o que la vehicule adecuadamente). Pero otros, sólo podrían desplegar esa vinculatoriedad inter privatos a través del poder público (normalmente el legislador, sea de la Unión o de los Estados miembros).

\section{Una problemática actual: la eficacia horizontal de los derechos de la Carta desde su conexión con una Directiva}

Llegados aquí, lo que mejor corresponde es analizar la jurisprudencia del TJ acerca de esa eficacia horizontal de los derechos de la Carta. Una jurisprudencia que, como es sabido, viene derivada de las cuestiones prejudiciales planteadas por el Juez nacional que actúa como Juez comunitario, que es, también aquí, entre particulares, el garante común de los DF reconocidos por la Unión ${ }^{34}$.

Puestos a ello, se detecta que un problema, quizás el principal, que refleja en la actualidad la Jurisprudencia del TJ en esta materia es el que conecta la eficacia entre particulares de los derechos de la Carta con las Directivas. La cuestión, en concreto, consiste en saber hasta qué punto se puede dar esa eficacia a través o en conexión con las Directivas, sabiendo que éstas, por definición, no pueden desarrollarla en las relaciones horizontales, esto es, entre particulares. O a la inversa: el problema es saber si las directivas que «derivan» de derechos de la Carta, o concretan derechos de la misma, pueden — desde esa conexión- tener efectos aplicativos entre particulares.

Tal y como lo planteó muy bien el Abogado General Yves Bot en sus Conclusiones al asunto Kücükdeveci, habida cuenta de que el Derecho de la Unión se inmiscuye cada día más en las relaciones entre particulares, irán en aumento los supuestos que planteen, en litigios entre particulares, la cuestión de la eficacia (invocabilidad) de las Directivas que contribuyen a garantizar los Derechos Fundamentales (especialmente, una vez que la Carta adquiere fuerza jurídica vinculante), recordando que muchos de los derechos de la Carta «figuran en el acervo comunitario en forma de directivas» ${ }^{35}$.

Pensemos, por poner algunos ejemplos de esa relación de conexión entre derechos de la Carta y Directivas, la que se da entre: el derecho de información

34 Como el objeto de nuestro análisis es la eficacia horizontal de la Carta, en adelante nos ceñiremos, básicamente, a la jurisprudencia al respecto posterior a la entrada en vigor de la Carta (2009), sin perjuicio de que, como se ha dicho, existan diversas resoluciones del Tribunal acerca de la eficacia inter privatos en materia de libertades fundamentales o de los DF en cuanto principios generales del Derecho comunitario y/o de la Unión, alguna de las cuales tendremos ocasión de recordar en lo que sigue.

35 Conclusiones de 7 de julio de 2009 (C-555/07), apdo. 90. 
y consulta de los trabajadores en la empresa (art. de la 27 Carta), en conexión con la Directiva 2002/14/CE, por la que se establece un marco general relativo a la información y a la consulta de los trabajadores en la UE (relación que fue el objeto de la conocida Sentencia AMS del Tribunal, sobre la que volveremos más adelante); el derecho a unas condiciones de trabajo justas y equitativas (artículo 31 de la Carta) en vínculo con la Directiva 2003/88/CE, relativa a determinados aspectos de la ordenación del tiempo de trabajo (que aparece en el asunto Domínguez, en relación al derecho a vacaciones anuales retribuidas ${ }^{36}$ ); el principio de no discriminación (art. 21 de la Carta), sea por edad, sexo, orientación sexual, discapacidad, religión, etc., en relación con la Directiva 2000/78/ CE del Consejo, relativa al establecimiento de un marco general para la igualdad de trato en el empleo y la ocupación (conexión que ha sido objeto de resoluciones del Tribunal, como la reiterada Sentencia Kücïkdeveci), o con la Directiva 1999/70/CE concerniente al trabajo de duración determinada; la protección del trabajador en caso de despido improcedente (artículo 30), en relación, por ejemplo, con la Directiva 98/59/CE relativa a la aproximación de las legislaciones de los Estados referida a los despidos colectivos ${ }^{37}$; la prohibición del trabajo de los niños y la protección de los jóvenes en el trabajo (artículo 32), en relación con la Directiva 94/33/CE relativa a la protección de los jóvenes en el trabajo; la garantía de poder conciliar la vida familiar y la vida profesional (artículo 33), respecto a la Directiva 92/85/CEE para promover la mejora de la seguridad y de la salud en el trabajo de la trabajadora embarazada, que haya dado a luz o en período de lactancia, o a la Directiva 2010/18/UE sobre el permiso parental; etc.

La cuestión clave es, pues, saber si esa identificación o conexión entre Derechos de la Carta y Directivas conexas permite o no constatar su eficacia horizontal, o mejor dicho, permite «fortalecer su invocabilidad $»^{38}$, cuando, se insiste, las Directivas no pueden desarrollarla como tales ${ }^{39}$. Si echamos un vistazo a la Jurisprudencia del TJ de esta última década, pueden observarse distintos casos que reflejan esta cuestión, siendo interesante destacar, a efectos descriptivos, los dos siguientes:

36 Ya mencionado a cuenta de las Conclusiones de la Abogado General V. Trstenjak, de 8 de septiembre de 2011 (Asunto C-282/19), siendo la Sentencia de fecha de 24 de enero de 2012.

37 O con la Directiva 2001/23/CE sobre mantenimiento de los derechos de los trabajadores en caso de traspasos de empresas.

38 Conclusiones del Abogado General Y. Bot al as. KÜCÜKDEVECI, cit., apdo. 90.

39 Hay que advertir, en todo caso, que la operatividad de la directiva como concreción de un derecho o de un principio general de Derecho de la Unión, en las relaciones verticales y horizontales, dependerá de que la actuación en cuestión entre en el ámbito o radio de acción de la Unión, y para que eso suceda, si el único elemento de conexión es la propia Directiva, deberá haber transcurrido el plazo de transposición de la misma [cosa que sucede en KÜCÜKDEVECI; pero no, por ejemplo, en BARTSCH (STJ de 23 de septiembre de 2008, C-427/06); en MANGOLD, no había finalizado el plazo de la Directiva 2000/78, pero sí de otra, la Directiva 1999/78/CE, relativa al trabajo de duración determinada, que sí era de aplicación en el caso]. Sobre ello, por ejemplo, R. Alonso García, Sistema jurídico de la Unión, op. cit., p. 294. 
a) El primer asunto es el de la Sentencia Kücükdeveci $i^{40}$, donde están en juego la eficacia del principio de no discriminación por razón de la edad y de la Directiva 2000/78, relativa al establecimiento de un marco general para la igualdad de trato en el empleo y la ocupación. Se trata de una petición prejudicial que se presenta en el marco de un litigio entre dos particulares, por una parte, la Señora Seda Kücükdeveci, y por otra, su antigua empresa, la compañía Swedex, un litigio relativo al cómputo del plazo de preaviso aplicable a efectos de su despido.

El caso, brevemente apuntado, es el siguiente: la Sra. Kücükdeveci entró a trabajar en la empresa con 18 años y fue despedida con 28 , con un plazo de preaviso de un mes. Esto es, el plazo se había calculado como si la trabajadora tuviese una antigüedad de 3 años, pese a que prestaba sus servicios desde hacía 10 años, correspondiéndole en este caso un plazo de preaviso de 4 meses. El hecho es que, según la legislación alemana (art. 622.2 BGB o Código Civil Alemán), no debían tomarse en cuenta, a efectos del cálculo del preaviso, los períodos de empleo completados antes de cumplir los 25 años de edad.

Ante ello, la Sra. Kücükdeveci impugnó su despido invocando que dicha norma nacional constituye una medida discriminatoria por razón de edad, contraria al Derecho de la Unión, debiendo excluirse su aplicación. El juez nacional alemán encargado de resolver este litigio decidió plantear una cuestión prejudicial preguntando si la eventual existencia de una discriminación directa por razón de la edad debía ser apreciada a la luz del principio general del Derecho de la Unión a no ser discriminado (como parecía sugerir la previa sentencia Mangold del TJ ${ }^{41}$ ), o bien a la luz de la Directiva 2000/78.

En su respuesta el Tribunal de Justicia constata la eficacia horizontal o entre particulares del principio de no discriminación por razón de la edad, como

40 Sentencia de 19 de enero de 2010, C-555/07. Sobre la Sentencia, entre otros: M. DE MoL, «Kücükdeveci: Mangold Revisited-Horizontal Direct Effect of a General Principle of EU Law. Court of Justice of the European Union (Grand Chamber) Judgment of 19 January 2010, Case C-555/07, Seda Kücükdeveci v. Swedex GmbH \& Co. KG», European Constitutional Law Review, 6, 2010, pp. 293 y ss.; S. SEver, «General Principles of Law and the Charter of Fundamental Rights», en Cabiers de Droit Européen, 1, 2016, pp. 167 y ss., esp. pp. 177 y ss.

41 Sentencia de 22 de noviembre de 2005, C-144/04. El Tribunal de Justicia dispondrá en la misma que la mencionada Directiva 2000/78 no establece por sí misma el principio de igualdad de trato en materia de empleo y ocupación, teniendo únicamente por objeto (art. 1) «establecer un marco general para luchar contra la discriminación por motivos de religión o convicciones, de discapacidad, de edad o de orientación sexual», y que «el principio mismo de prohibición de estas formas de discriminación encuentra su fuente en distintos instrumentos internacionales y en la tradiciones constitucionales comunes a los Estados miembros» (apdo. 74). En este sentido, «por lo tanto, el principio de no discriminación por razón de la edad debe ser considerado un principio general del Derecho comunitario» (apdos. 74 y 75). Y sobre esta base, la Sentencia concluirá declarando que corresponde al órgano jurisdiccional nacional garantizar la plena eficacia del mencionado principio, «dejando sin aplicación cualesquiera disposiciones de la Ley nacional contrarias, incluso aunque no haya expirado todavía el plazo de adaptación del Derecho interno a dicha Directiva» (apdo. 78). 
aplicación específica del principio general del Derecho de la Unión a la igualdad de trato, pero reconociendo esa eficacia horizontal «tal como se concreta en la Directiva» 2000/78, esto es, sin reconocer dicha eficacia de forma aislada ni a la Directiva ni al principio general ${ }^{42}$ (principio que está reconocido hoy en el art. 21 de la Carta $\left.{ }^{43}\right)$, una eficacia que excluye la aplicación de la norma nacional contraria (regulando las relaciones inter privatos) ${ }^{44}$.

En concreto, el Tribunal de Justicia sentenció que el principio de no discriminación por razón de la edad, "tal como se concreta en la Directiva 2000/78/CE (...), debe interpretarse en el sentido de que se opone a una normativa nacional» como la señalada (que establecía que los períodos de trabajo completados por el trabajador antes de alcanzar los 25 años de edad no se tenían en cuenta a efectos del cálculo del plazo de preaviso de despido). Recuerda, además, que es el Juez nacional competente para resolver el caso quien deberá dejar sin aplicación cualquier actuación nacional contraria al principio así entendido (con independencia del ejercicio de la facultad de plantear la prejudicial sobre el mismo $)^{45}$.

Esta resolución, que, como se ha dicho, sigue y desarrolla la previa Sentencia Mangold, encuentra una confirmación y proyección ulterior en la reciente Sentencia Dansk Industri ${ }^{46}$. Una Sentencia que recalca, también, que ni los principios generales de seguridad jurídica o de confianza legítima, ni la posibilidad del particular de acudir a reclamar la responsabilidad extracontractual del Estado por los daños causados en infracción del Derecho de la Unión, pueden hacer cuestionar la obligación del «órgano jurisdiccional nacional que conoce de un litigio entre particulares comprendido en el ámbito de aplicación de la

42 Véanse, sobre el efecto directo horizontal de los principios generales y sus límites, las Conclusiones de los siguientes Abogados Generales: las de Tizzano, de 30 de junio de 2005, en el asunto MANGOLD, puntos 83, 84 y 100; las del Abogado General Mazák, de 15 de febrero de 2007, en el asunto PALACIOS DE LA VILLA (sentencia de 16 de octubre de 2007, C-411/05), puntos 133 a 138; las conclusiones de Sharpston, de 22 de mayo de 2008, en el asunto BARTSCH (sentencia de 23 de septiembre de 2008, C-427/06), puntos 79 a 93; J. Kokott, en los siguientes asuntos: AKZO Y AKROS/COMISIÓN (de 29 de abril de 2010, C-550/07 P, apdo. 96), ROCA ÁLVAREZ (de 6 de mayo de 2010, C-104/09, apdos. 53 y ss.) y O. ANDERSEN (también de 6 de mayo de 2010, C-499/08, apdos. 21 y ss.); o V. Trstenjak en M. DOMÍNGUEZ, cit., apdos 89 y ss. y 115 y ss. Véanse, asimismo, los trabajos publicados en el n. ${ }^{\circ} 52$ de Cabiers de Droit Européen (2016), dedicado monográficamente a los principios generales del Derecho de la Unión.

43 Art. 21 («No discriminación»): «1. Se prohíbe toda discriminación, y en particular la ejercida por razón de sexo, raza, color, orígenes étnicos o sociales, características genéticas, lengua, religión o convicciones, opiniones políticas o de cualquier otro tipo, pertenencia a una minoría nacional, patrimonio, nacimiento, discapacidad, edad u orientación sexual. // 2. Se prohíbe toda discriminación por razón de nacionalidad en el ámbito de aplicación de los Tratados y sin perjuicio de sus disposiciones particulares».

44 Ahora bien, es interesante recordar la idea del Abogado General del caso, Yves Bot, destacando en sus conclusiones que: «antes de acudir al principio de no discriminación por razón de la edad como solución última para resolver los conflictos entre el Derecho de la Unión y el Derecho nacional, los tribunales nacionales, en consecuencia, han de comprobar debidamente que su Derecho interno no puede ser interpretado de conformidad con la Directiva 2000/78» (apdo. 48).

45 Apartados 51 y ss. de la Sentencia.

46 De 19 de abril de 2016 (C-441/14), apdo. 27. 
Directiva 2000/78, cuando aplica las normas de su Derecho nacional, [de] interpretarlas de manera que puedan aplicarse de conformidad con dicha Directiva o, si tal interpretación conforme es imposible, dejar inaplicados, en caso necesario, cualesquiera preceptos del Derecho nacional que sean contrarios al principio general de no discriminación por razón de la edad» ${ }^{47}$.

Procede señalar que esta Jurisprudencia Kücükdeveci (o, si se prefiere, la secuencia jurisprudencial Mangold-Kücükdeveci-Dansk Industri) tiene, obviamente, incidencia o proyección en el ámbito de los Estados miembros. Es el caso de lo que está sucediendo en España, por ejemplo, en relación con la también reciente Sentencia del TJ Diego Porras ${ }^{48}$, que reconoce el principio de no discriminación —en materia de indemnización por finalización del contrato de trabajo de interinidad- de los trabajadores temporales respecto a los fijos sobre la base de la ya mencionada Directiva 1999/70 sobre trabajo de duración determinada ${ }^{49}$.

El hecho es que, siguiendo esta Sentencia del $\mathrm{TJ}^{50}$, la Sala de lo Social del Tribunal Superior de Justicia del País Vasco emitió, el día 18 de

47 Apartado 43 de la Sentencia. Sobre el tema: E. GuAlCo y L. Lourenço, «'Clash of Titans'. General Principles of EU Law: Balancing and Horizontal Direct Effect», en European Papers (Online Journal), http:// www.europeanpapers.eu/en/europeanforum/clash-titans-general-principles-eu-law-balancing-and-horizontal-direct-effect (08.08.2006). Es interesante señalar que, desconociendo abiertamente esta sentencia prejudicial, el Tribunal remitente (Tribunal Supremo Danés) ha declarado, en Sentencia de 6.12.2016, que el Acta danesa de Adhesión no contemplaría la posibilidad de que los principios generales del Derecho de la Unión (art. 6.3 TVE) sean directamente aplicables inter privatos en Dinamarca, y no proveería la base jurídica para inaplicar la norma nacional que los contradiga (de hecho, la sentencia del Tribunal Supremo desestima el recurso de la parte demandante, una vez recaída la prejudicial).

48 STJ de 14 de septiembre de 2016, C-596/2014. Al respecto, por ejemplo, I. GonZÁLEZ DEL REY RoDríguez, «Igualdad de los trabajadores temporales e indemnización por finalización del contrato: la STJUE de 14 de septiembre de 2016 (De Diego Porras, C-596/2014). ¿Un paso (más) hacia el 'contrato único’?", La ley Unión Europea, 42, 2016, pp. 24 y ss.

49 En concreto en relación con la cláusula 4 del Acuerdo marco (sobre el trabajo de duración determinada, que figura en el anexo de la Directiva 1999/70) titulada «Principio de no discriminación», que establece en su apartado 1: «Por lo que respecta a las condiciones de trabajo, no podrá tratarse a los trabajadores con un contrato de duración determinada de una manera menos favorable que a los trabajadores fijos comparables por el mero hecho de tener un contrato de duración determinada, a menos que se justifique un trato diferente por razones objetivas».

50 Esta Sentencia (respecto a un contrato temporal en el Ministerio de Defensa español) es quizás la más llamativa de las tres que dictó el TJ, resolviendo en la misma fecha tres prejudiciales planteadas por órganos jurisdiccionales españoles [las otras dos son la referente al as. M.E. PÉREZ LÓPEZ (C-16/15; en relación a un contrato en la Sanidad madrileña) y la de los as. ac. MARTÍNEZ ANDRÉS Y CASTREJANA (C-184 y 197/15, en relación a prestaciones en un caso en el Servicio Vasco de Salud y en el otro en el Ayuntamiento de Vitoria), versando también ambas sobre la cláusula 4 del Acuerdo marco sobre el trabajo de duración determinada que figura como anexo de la Directiva 1999/70/CE]. Ello es debido a que viene a reconocer, con base en la mencionada Directiva, una indemnización para supuestos de extinción de contrato de trabajo de duración determinada no previstos en la legislación española. Sentencias todas ellas en la línea de otras resoluciones prejudiciales previas — planteadas desde España — también relacionadas con la Directiva mencionada (véanse: DEL CERRO ALONSO, 13 de septiembre de 2007, as. C-307/05; GAVIEIRO GAVIEIRO $e$ IGLESIAS TORRES, 22 de diciembre de 2010, as. ac. C-444 y C-456/09; MONTOYA MEDINA, 18 de marzo de 2011, Auto 273/10; ROSADO SANTANA, 8 de septiembre de 2011, as. C-177/10; LORENZO MARTÍNEZ, 9 de febrero de 2012, as. C-556/11). 
octubre de 2016, dos Sentencias relacionadas con esta cuestión. En la primera, la Sentencia 1962/2016 (rec. 1690/2016), se equiparan los contratos fijos a los temporales —en concreto, interinos - a efectos de indemnización por despido (el del trabajador con contrato temporal y el del fijo despedido por causas objetivas) en una relación laboral en el ámbito del sector público (la persona con contrato temporal trabajaba en una Fundación ligada a la Sanidad Pública Vasca). Pero la cosa no quedó ahí (relación vertical: Particular/Administración Pública), pues la segunda Sentencia, la 2016/2016 (rec. 1872/16), extenderá al sector privado, es decir, a una relación horizontal o inter privatos, los efectos del pronunciamiento de la mencionada STJ De Diego Porras, sobre la discriminación de que son objeto los trabajadores temporales cuando finaliza la relación laboral, en comparación con los que tienen un contrato fijo, estableciendo una indemnización de veinte días —en lugar de doce- a la finalización de un contrato por obra o servicio determinado a favor de un trabajador de una empresa privada (trabajador de una empresa de servicios).

Esta extensión de la no discriminación a efectos de indemnización del sector público al sector privado se hace desde la «conexión» de la Directiva 1999/70 —que, por definición, no puede tener efecto directo en las relaciones horizontales - con el Derecho Fundamental del art. 21 de la Carta (en línea con la sentencia Dansk Industri, a la que se (ita) $)^{51}$.

Merece la pena señalar que se han pronunciado en idéntico sentido, respecto a la relación en el ámbito público, el Tribunal Superior de Justicia de Madrid (Sentencia de 5 de octubre de 2016, 8982/2016), y el de Andalucía (Sentencia 1778/2016, rec. 1515/2016, de 16 de noviembre de 2016, sobre una relación laboral con el Ayuntamiento de Marbella ${ }^{52}$ ). Sin embargo, otra Sentencia del mismo TSJA (rec. 1539/2016), en un contrato de obra o servicio formalizado por una

51 «...] queremos hacer hincapié en el art. 21.1, de la Carta de Derechos Fundamentales de la Unión Europea, que, destaquemos, forma parte de lo que se ha venido a considerar derecho originario europeo, al establecer que: «... Se prohíbe toda discriminación, y en particular la ejercida por razón de sexo, raza, color, orígenes étnicos o sociales, características genéticas, lengua, religión o convicciones, opiniones políticas o de cualquier otro tipo, pertenencia a una minoría nacional, patrimonio, nacimiento, discapacidad, edad u orientación sexual...». Precepto que es directamente aplicable en un litigio entre particulares, como el actualmente en curso, con todas sus consecuencias. Y siempre sin olvidar la expresa referencia que incorpora el $n .^{\circ} 1$, de la Cláusula 4, del Acuerdo Marco [que figura en el anexo de la Directiva 1999/70] al principio de no discriminación en materia laboral. Así entendemos que lo ha venido a ratificar no sólo la resolución de 14-9-2016 [del TJ de la UE, as. De Diego Porras, C-596/2014], sino con anterioridad las ya mencionadas, así como la de 19-4-2016, C-441/14 [as. Dansk Industri], al reconocer que el citado es «un principio general del Derecho de la Unión» (FJ n. ${ }^{\circ} 8$ de la Sentencia 2016/2016 de la Sala de lo Social del TSJPV; énfasis y corchetes añadidos).

52 En idéntico sentido, de la misma Sala y fecha, la recaída en el rec. 1411/2016. 
empresa privada, denegará la indemnización debido a ese carácter privado de la empleadora y a que las Directivas de la UE no pueden tener eficacia horizontal inter privatos $^{53}$. Como recuerda la doctrina, la casación está servida ${ }^{54}$.

b) El otro asunto significativo que importa destacar aquí es el de la Sentencia AMS (Association de Médiation Social) ${ }^{55}$, en la que el TJ analiza la aplicabilidad, en una relación entre particulares, del art. 27 relativo al «derecho a la información y consulta de los trabajadores en la empresa» ${ }^{56}$.

La resolución trae causa de una petición de decisión prejudicial sobre la interpretación de este artículo de la Carta y de la Directiva 2002/14/CE, por la que se establece un marco general relativo a la información y a la consulta de los trabajadores en la Comunidad Europea ${ }^{57}$. Según ésta, a partir de cierto número de personal de una empresa deben elegirse delegados de personal o debe designarse un representante sindical y crearse un comité de empresa. Francia transpuso la Directiva, previendo en particular que algunas categorías de trabajadores (como los aprendices, los titulares de un

53 Según se señala en el sumario de la Sentencia: «Las Directivas de la Unión Europea no tienen efecto directo horizontal, entre particulares — a estos efectos, la empresa demandada es un particularexcepto en el caso de que desarrollen normas antidiscriminatorias. Y de acuerdo con los Tratados de la Unión Europea el tratamiento diferente entre trabajadores fijos y trabajadores temporales no puede considerarse como una discriminación en sentido propio. Por ello, la Sala concluye, al contrario que la sentencia de la Sala de lo Social del Tribunal Superior de Justicia del País Vasco de 18 de octubre de 2016 (recurso 1872/2016), que el contenido de la antes aludida sentencia del Tribunal de Justicia de la Unión Europea [as. De Diego Porras] no tiene efecto directo en la relación laboral de demandante y empresa demandada, y que tampoco cabe hacer una «interpretación conforme» del artículo 49.1 c) del Estatuto de los Trabajadores con el contenido de dicha sentencia, dados los términos claros y contundentes que no dejan lugar a dudas de que la indemnización correspondiente al cese del contrato temporal de la demandante era de doce días por año de duración del mismo».

54 I. Beltrán de Heredia, «Diego Porras: El carácter privado de la empleadora impide indemnización de 20 días a contrato de obra y servicio (STSJ Andalucía 16/11, rec. 1539/16)», en su Blog: Una mirada crítica a las relaciones laborales (de 30 de noviembre de 2016): http://ignasibeltran.com/2016/11/30/diego-porras-el-caracter-privado-de-la-empleadora-impide-indemnizacion-de-20-dias-a-contrato-de-obra-y-servicio-stsj-andalucia-1611-rec-153916/, in fine.

55 De 15 de enero de 2014, C-176/12. Sobre la Sentencia, entre otros: J. GArcía Murcia, «Naturaleza y fuerza vinculante de los derechos fundamentales en la Unión Europea: a propósito de las previsiones sobre información y consulta en materia laboral», REDE, 52, 2014, pp. 91 y ss.; C.C. MURPHY, «Using the EU Charter of Fundamental Rights Against Private Parties after Association de Médiation Sociales», European Human Rights Law Review, 170, 2014 (disponible en: http://ssrn.com/abstract=2400491); Dubout, E., «Principes, droits et devoirs dans la Charte des droits fondamentaux de l'Union européenne: à propos de arrêt CJUE, 14 janvier 2014, C-176/12, Association de médiation sociales», Rev. Trim. Dr. Eur., 2, 2014, pp. 409 y ss.; N. CARIAT, «L'invocation de la Charte des droits fondamentaux de l'Union européenne dans les litiges horizontaux — État des lieux après l'arrêt Association de médiation sociale», Cabiers de Droit Européen, 2, 2014, pp. 305 y ss.; S. SEver, «General Principles of Law and the Charter...», op. cit., pp. 182 y ss.

56 Art. 27 CDFUE: «Deberá garantizarse a los trabajadores o a sus representantes, en los niveles adecuados, la información y consulta con suficiente antelación, en los casos y condiciones previstos en el Derecho de la Unión y en las legislaciones y prácticas nacionales».

57 De 11 de marzo de 2002 (DO L 80, p. 29). 
contrato de iniciativa para el empleo, etc.) debían excluirse del cómputo del personal de la empresa a estos efectos. Basándose en esas exclusiones de la normativa francesa, la AMS impugnará la designación de un representante sindical dentro de la misma, debido a que no llegaba al umbral mínimo para tal designación. Ante ello el representante sindical designado y varias asociaciones sindicales alegarán que esas exclusiones del Derecho francés van en contra del Derecho de la Unión. Llegado el asunto a la Corte de Casación, ésta preguntará al TJ si el artículo 27 de la Carta, según viene precisado en la mencionada Directiva, puede ser invocado en un litigio entre particulares para excluir la aplicación de la disposición nacional (Código de Trabajo) de transposición contraria al Derecho de la Unión.

La petición prejudicial versa, a la postre, sobre si es posible invocar el art. 27 de la Carta, por sí sólo o en combinación con la Directiva, para inaplicar la norma francesa que excluye a esas categorías de trabajadores, impidiendo con ello que se cumpla con el umbral mínimo de personal para nombrar representante.

El Tribunal de Luxemburgo, tras constatar que la norma francesa es contraria a la Directiva y que ésta carece de eficacia horizontal, se planteará, como paso subsiguiente, si este caso es similar al asunto Kücükdeveci y puede resolverse conforme al mismo, esto es, «de modo que el artículo 27 de la Carta, por sí solo o en combinación con las disposiciones de la Directiva 2002/14, pued[a] ser invocado en un litigio entre particulares a efectos de inaplicar, en su caso, la disposición nacional no conforme con la Directiva ${ }^{58}$.

El Tribunal responderá que ello no es posible. La razón estriba en que, mientras en Kücükdeveci el principio de no discriminación por razón de la edad (reconocido en el art. 21 de la Carta) «es suficiente por sí mismo para conferir a los particulares un derecho subjetivo invocable como tal» ${ }^{59}$, no ocurre lo mismo con el derecho del asunto AMS. Para el TJ el art. 27 no es suficiente por sí mismo para conferir a los particulares un derecho subjetivo invocable como tal, y por tanto, tampoco en combinación con la Directiva ${ }^{60}$, pues, según el mismo, «para que produzca plenamente sus efectos debe ser precisado por disposiciones del Derecho de la Unión o del Derecho nacional» ${ }^{61}$.

58 Apartado 41 de la Sentencia.

59 Apartado 47 de la Sentencia AMS.

60 Apartados 48 y 49. El Tribunal recordará que, ante ello, la parte perjudicada puede invocar la jurisprudencia relativa al reconocimiento de la responsabilidad patrimonial del Estado por los daños causados en infracción del Derecho de la Unión, y obtener así, en su caso, la reparación del daño sufrido (la misma solución a la que, por cierto, llegó en el as. M. DOMÍNGUEZ).

61 Ibid., apdo. 45. En este sentido, concretará en el apartado siguiente: «en efecto, la prohibición, enunciada en el artículo 3, apartado 1, de la Directiva 2002/14 y dirigida a los Estados miembros, de excluir del cómputo del personal de la empresa a una categoría específica de trabajadores que inicialmente forman 
Paradójicamente, aunque esta Sentencia niega la eficacia horizontal o inter privatos del artículo 27 de la Carta en el litigio en cuestión, parece claro, como aprecia la mayoría de la doctrina, que la argumentación esgrimida está reconociendo la posible existencia de Derechos Fundamentales de la misma que pueden desplegarla. Ello dependería de que la disposición de la Carta que reconoce el Derecho Fundamental en cuestión «sea susceptible por sí misma para conferir a los particulares un derecho subjetivo invocable como tal». Característica que ahora se reconoce al principio de no discriminación por razón de la edad del art. $21^{62}$ (recordemos que en el asunto Kücükdeveci se reconoció esa eficacia a dicho Derecho en su formato de principio general del Derecho de la Unión ${ }^{63}$ ).

Por lo demás, late aquí, en esta Sentencia, otra cuestión importante que vale la pena apuntar, cuestión que parte de la ya señalada distinción entre «derechos» y «principios» que contiene la Carta, tal y como se explicita en el art. 52.5 de la misma. Según se desprende de la Sentencia, parece claro que el artículo 27 no contiene un «derecho» vindicable directamente ante la jurisdicción competente, sino más bien un «principio» rector. Pues bien, la doctrina especializada llama la atención acerca de que en esta Sentencia el Tribunal está desconociendo u omitiendo el reconocimiento de la naturaleza misma de los principios rectores de la política social incorporados en la Carta. "Y es que, en efecto, una cosa es exigir que dichos principios requieran de una intervención del legislador de la Unión y/o los Estados miembros para resultar plenamente operativos ante los tribunales, y otra bien distinta negarles operatividad alguna cuando se ha producido dicha intervención; operatividad que en tal supuesto debería ser plena en términos reaccionales, a los efectos de cotejar la compatibilidad de la legislación interna con el principio rector a la luz de su concreción por el instrumento de la Unión correspondiente (en el caso, por la Directiva 2002/14/CE, que el Tribunal debería haber entendido, como sostuvo el Abogado General Cruz Villalón, «como un supuesto de concreción esencial e inmediata del artículo 27 de la Carta y, por tanto, susceptible de integrarse en el contenido justiciable del mismo»)» ${ }^{64}$.

parte de las personas que se deben considerar en ese cómputo no puede deducirse, como regla jurídica directamente aplicable, del texto del artículo 27 de la Carta ni de las explicaciones referidas a ese artículo».

62 Señalando que la STJ AMS reconoce la Drittwirkung del art. 21 de la Carta: S. SEvEr, «General Principles of Law and the Charter...», op. cit., pp. 189 y ss.; S. PEers, «When does the EU Charter of Rights apply to private parties?», EU Law Analysis Blog, 15/01/2014, apdo. comments.

63 Así aparece en los apartados 21, 27 o 50 de la misma, mientras la alusión a que dicho principio general está recogido en el artículo 21 es realizada de forma más bien previa o tangencial en el apartado 22.

64 R. Alonso García, Sistema jurídico de la Unión Europea, op. cit., p. 295; véase, asimismo, J. García Murcia, «Naturaleza y fuerza vinculante de los derechos fundamentales en la Unión Europea ...», op. cit., espec. punto 5. Algo similar ocurre también, a juicio de Ricardo Alonso, en el asunto GLATZEL — de 22 de 


\section{Algunas conclusiones}

La primera conclusión que podemos señalar es que la Carta contiene, a juicio del Tribunal, artículos que despliegan una eficacia horizontal o entre particulares, siempre que la disposición en cuestión «sea susceptible por sí misma para conferir a los particulares un derecho subjetivo invocable como tal» (por ejemplo, la del art. 21). Si la disposición contiene un derecho invocable como tal, podrá desarrollar esa eficacia horizontal por sí mismo o en combinación con una Directiva. Y el hecho es que existe una serie de Directivas que vienen a desarrollar y garantizar el contenido de muchos derechos de la Carta y que, aun no disponiendo por sí mismas de eficacia horizontal, pueden desplegarla así en conexión con un DF de la Carta.

En segundo lugar, parece que el Tribunal no reconoce todavía una eficacia horizontal reaccional (o invocabilidad de exclusión) a los «principios» de la Carta, tal y como es posible apreciar en el caso $A M S$. Pero, cabe entender, que el hecho de que la Carta tenga artículos que recojan «principios» rectores, y no «derechos» invocables como tales (por no configurar posiciones subjetivas individualizadas), no implica que esos principios carezcan de una operatividad a efectos reaccionales (si se han visto concretados por el legislador), esto es, a efectos de impedir la aplicación de una norma nacional contraria en las relaciones entre particulares.

En tercer lugar, y si echamos un vistazo a la jurisprudencia del TJ recaída desde que la Carta entró en vigor (2009), es posible destacar que la cuestión o la casuística acerca de la eficacia horizontal de los derechos de la Carta se manifiesta de forma clara — siguiendo la terminología de la Carta— en el ámbito de los derechos de $\ll$ igualdad ${ }^{65}$ y de $«$ solidaridad» ${ }^{66}$, sin perjuicio de que haya

mayo de 2014, C-356/12 - en este caso en relación al principio de no discriminación por razón de discapacidad y a la integración de las personas discapacitadas del art. 26 de la Carta («la Unión reconoce y respeta el derecho de las personas discapacitadas a beneficiarse de medidas que garanticen su autonomía, su integración social y profesional y su participación en la vida de la comunidad») (ibid., p. 396).

Recordemos en todo caso que, según establecen las Explicaciones relativas al artículo 52, apartado 5, de la Carta: «Los principios pueden aplicarse mediante actos legislativos o ejecutivos (adoptados por la Unión en función de sus competencias y por los Estados miembros solamente en aplicación del Derecho de la Unión); por consiguiente, son importantes para los tribunales sólo cuando se trata de la interpretación o revisión de dichos actos. Sin embargo, no dan lugar a derechos inmediatos de acciones positivas de las instituciones de la Unión o de las autoridades de los Estados miembros, lo que es coherente tanto con la jurisprudencia del Tribunal de Justicia (...) como con el planteamiento de los sistemas constitucionales de los Estados miembros respecto de los «principios», en particular en el ámbito del Derecho social. A título ilustrativo, ejemplos de principios reconocidos por la Carta incluyen, entre otros, los artículos 25, 26 y 37. En determinados casos, un artículo de la Carta puede incluir elementos que se derivan de un derecho y de un principio, por ejemplo, los artículos 23, 33 y $34 »$.

65 Título III de la Carta (arts. 20 a 26): igualdad ante la ley; no discriminación; diversidad cultural, religiosa y lingüística; igualdad entre hombres y mujeres; derechos del menor; derechos de las personas mayores; e integración de las personas discapacitadas.

66 Título IV de la Carta (arts. 27 a 38), que, recordémoslo, engloba los derechos: a la información y consulta de los trabajadores en la empresa; de negociación y acción colectiva; de acceso a los servicios de 
supuestos relativos a otros derechos (como el asunto Google en relación al derecho al olvido como contenido del derecho a la protección de datos ${ }^{67}$ ).

Si miramos adelante, parece que esta va a ser la tónica que va a continuar, y además, sobre derechos en relación a Directivas. Así lo demostrarían, por ejemplo, tres asuntos sobre los que acaban de publicarse, este verano pasado, las respectivas Conclusiones de las Abogados Generales, y sobre los que está a punto de recaer Sentencia del TJ. En efecto, ahí están, por una parte, los asuntos Samira Achbita $^{68}$ y Bougnaoui ${ }^{69}$, en los que, expresado ahora de forma esquemática, la cuestión consiste — de forma similar aunque no idéntica- en si un empresario privado puede o no prohibir a una trabajadora de religión musulmana llevar velo en el trabajo, y si puede o no despedirla por negarse ella a quitárselo. Cuestiones a responder desde el prisma de la ya mencionada Directiva 2000/78 de lucha contra la discriminación, tanto directa como indirecta ${ }^{70}$, en el empleo y la ocupación en conexión con el principio de no discriminación (art. 21 de la Carta), en este

colocación; de protección en caso de despido injustificado; derecho a condiciones de trabajo justas y equitativas; prohibición del trabajo infantil y protección de los jóvenes en el trabajo; protección y conciliación de la vida familiar y de vida profesional; derecho a la seguridad social y ayuda social; derecho a la protección de la salud; de acceso a los servicios de interés económico general; y protección del medio ambiente y de los consumidores.

67 STJ de 13 de mayo de 2014, GOOGLE vs. AEPD y Mario Costeja González, C-131/12. La Sentencia reconoce el derecho al olvido, señalando que el tratamiento de datos personales efectuado por un motor de búsqueda «puede afectar significativamente a los derechos fundamentales de respeto de la vida privada y de protección de datos personales cuando la búsqueda realizada sirviéndose de ese motor de búsqueda se lleva a cabo a partir del nombre de una persona física, toda vez que dicho tratamiento permite a cualquier internauta obtener mediante la lista de resultados una visión estructurada de la información relativa a esta persona que puede hallarse en Internet, que afecta potencialmente a una multitud de aspectos de su vida privada, que, sin dicho motor, no se habrían interconectado o sólo podrían haberlo sido muy difícilmente y que le permite de este modo establecer un perfil más o menos detallado de la persona de que se trate. Además, el efecto de la injerencia en dichos derechos del interesado se multiplica debido al importante papel que desempeñan Internet y los motores de búsqueda en la sociedad moderna, que confieren a la información contenida en tal lista de resultados carácter ubicuo (véase, en este sentido, la sentencia eDate Advertising y otros, C-509/09 y C-161/10, EU:C:2011:685, apartado 45)» (apdo. 80). Sobre el tema, por ejemplo, D. CóRdoBA Castroverde, ElDerecho.com, de 1.10.2014; M. Hernández Ramos, «Motores de búsqueda y Derechos Fundamentales en internet. La STJUE GOOGLE C-131/12, de 13 de mayo de 2014», RGDE, 34, 2014, pp. 22 y ss.; A. Rallo Lombarte, «El debate europeo sobre el derecho al olvido en internet», en A. Rallo Lombarte y R. García Mahamut (Eds.), Hacia un nuevo Derecho europeo de protección de datos, Tirant lo Blanch, Valencia, 2015, pp. 703 y ss.; C.I. Álvarez Rigaudias, «Sentencia Google Spain y derecho al olvido», Actualidad Jurídica Uría Menéndez, 38, 2014, pp. 115 y ss. Véase, asimismo, M. PöscHL, «La garantía de los estándares de derechos humanos y fundamentales ante las nuevas amenazas que generan los particulares y los actores extranjeros», Teoría y Realidad Constitucional, 36, 2015, p. 103.

68 Con Conclusiones de la Abogado General J. Kokott, de 31 de mayo de 2016, C-157/15.

69 Con Conclusiones de la Abogado General E. Sharpston, de 13 de julio de 2016, C-188/15.

70 Debe recordarse que el artículo 2.2 de la Directiva distingue entre la discriminación «directa» (aquella que se da «cuando una persona sea, haya sido o pudiera ser tratada de manera menos favorable que otra en situación análoga») y la «indirecta» [que existe «cuando una disposición, criterio o práctica aparentemente neutros pueda ocasionar una desventaja particular a personas con una religión o convicción, con una discapacidad, de una edad, o con una orientación sexual determinadas, respecto de otras personas, salvo que: (...) dicha disposición, criterio o práctica pueda justificarse objetivamente con una finalidad legítima y salvo que los medios para la consecución de esta finalidad sean adecuados y necesarios»]. 
caso, por motivos religiosos ${ }^{71}$. El tercer asunto es el del caso David Parris, sobre no discriminación por razón de la edad y de la orientación sexual, en conexión con la misma Directiva 2000/78 de igualdad de trato en el empleo y la ocupación ${ }^{72}$.

\section{MARGEN DE ACTUACIÓN DEL JUEZ NACIONAL EN LA TUTELA (INTER PRIVATOS) DE LOS DERECHOS FUNDAMENTALES EN EL ÁMBITO DE APLICACIÓN DEL DERECHO DE LA UNIÓN EUROPEA}

El Juez encargado de tutelar los Derechos Fundamentales de la Unión Europea, tanto frente a las actuaciones de los Estados miembros como en las relaciones entre particulares (dentro del ámbito de aplicación del Derecho de la Unión), es el «Juez nacional», esto es, el órgano jurisdiccional nacional que actúa como Juez de aplicación del Derecho de la Unión, el Juez a quien compete, en cada caso, aplicar dicho Derecho (si bien esa función tuitiva debe ser ejercida a través de una relación esencial de cooperación con el Tribunal de Justicia, una cooperación que, como es sabido, se articula, principalmente, mediante la cuestión prejudicial, de interpretación o, en su caso, de validez, establecida en el art. $267 \mathrm{TFUE}^{73}$ ). Ahora

71 Ninguna de las dos Conclusiones presentadas aborda o alude explícitamente a la cuestión de la eficacia horizontal de los Derechos Fundamentales, aunque parece obvio que ambos casos pueden ser enfocados como asuntos en los que está en juego la eficacia entre particulares del principio de no discriminación por motivos religiosos. En todo caso, las dos Conclusiones están reconociendo implícitamente que el Derecho Fundamental a no ser discriminado por tales motivos está desarrollando su juego vinculante a través de la Directiva 2000/78 (y la legislación nacional de transposición), en la línea de la jurisprudencia KÜCÜKDEVECI y AMS. Así Sharpston recordará que «en cuanto a la discriminación por razón de la edad, el Tribunal de Justicia ha declarado que el principio de no discriminación debe considerarse un principio general del Derecho de la Unión que ha sido concretado por la Directiva 2000/78 en el ámbito del empleo y de la ocupación [recordando la STJ PRIGGE, aquí ya citada, apdo. 38]. La misma conclusión debe aplicarse al principio de no discriminación por motivos de religión o convicciones» (apdo. 62). Véase también el apartado 35 de las Conclusiones de Juliane Kokott en el as. ACHBITA.

72 El litigio en el que surge la petición prejudicial se produce entre el profesor Parris (demandante), y la parte demandada (por una parte, el Trinity College Dublin, su antiguo empleador, y, por otra, diversas autoridades relacionadas con el ámbito de la educación), por supeditarse, en un plan de previsión profesional, el derecho a una pensión de supervivencia a favor de la pareja del mismo sexo a la condición de que la unión civil registrada se constituyera antes de que el trabajador afiliado al plan cumpliese los 60 años de edad, cuando el hecho es que la ley no les permitía a los interesados contraer (matrimonio o) tal unión civil antes de alcanzar dicho límite de edad. Véanse las Conclusiones de la Abogado General J. Kokott al as., de 30 de junio de 2016 (C-443/15).

73 Conviene recordar a este último respecto la reiterada jurisprudencia del TJ relativa a que «desde el momento en que una normativa nacional entra en el ámbito de aplicación del Derecho comunitario, el Tribunal de Justicia, cuando conoce de un asunto planteado con carácter prejudicial, debe proporcionar todos los elementos de interpretación necesarios para la apreciación, por el órgano jurisdiccional nacional, de la conformidad de dicha normativa con los derechos fundamentales cuya observancia garantiza el Tribunal de Justicia, tal como están expresados, en particular, en el Convenio Europeo para la Protección de los Derechos Humanos y de las Libertades Fundamentales» (Sentencia TJ al asunto STEFFENSEN, de 10 de abril de 2003, C-276/01, apartado 70, en la que se hace referencia a jurisprudencia previa al respecto: sentencias de 
bien, como es conocido, ese Juez nacional se encuentra sometido a una doble vinculación, la que despliegan los Derechos Fundamentales de la Carta y la que despliegan los reconocidos en la Constitución nacional.

La pregunta que surge entonces es, dicho ahora de forma resumida, ¿Qué sistema de Derechos Fundamentales —el europeo de la Carta o el constitucional nacional - debe aplicarse en caso de conflicto o diversidad de estándares de protección? La respuesta, a tenor del artículo 6.1 TUE y del art. 51.1 de la Carta y del principio de primacía del Derecho de la Unión, es que el sistema de los DFUE (tal y como se ha evidenciado, por ejemplo, en un caso paradigmático en la materia, como es el asunto Melloni ${ }^{74}$ ).

No obstante, el Tribunal de Justicia ha matizado esta respuesta en sendas Sentencias emitidas en la misma fecha: en la propia STJ Melloni y en Akerberg $^{75}$, distinguiendo dos situaciones al respecto: (a) la primera es la que surge cuando un acto del Derecho de la Unión requiere medidas nacionales para su ejecución, sin que la actuación del Estado venga totalmente reglada; en tal supuesto, las autoridades y tribunales nacionales siguen estando facultados para aplicar estándares nacionales de protección de los derechos fundamentales. Pero eso sí, «siempre que esa aplicación no afecte al nivel de protección previsto por la Carta, según su interpretación por el Tribunal de Justicia, ni a la primacía, la unidad y la efectividad del Derecho de la Unión». (b) La segunda aparece, sensu contrario, cuando la aplicación nacional del Derecho de la Unión deba realizarse sin margen para adoptar aquellas medidas normativas internas; y en este caso no habrá otra posibilidad que aplicar el estándar iusfundamental de la Unión ${ }^{76}$ (si esta situación se da en el asunto Melloni, aquella, por el contrario, aparece escenificada en el asunto Akerberg).

Llegados aquí, resulta oportuno puntualizar que esta obligación de seguir los estándares de los Derechos Fundamentales de la Carta solapándolos a los parámetros nacionales, cuando proceda, debe ser tenida en cuenta por el Juez nacional incluso contra el parecer de resoluciones jurisdiccionales previas (de Tribunales superiores en grado, aunque se trate del Tribunal Constitucional del propio país) que le resulten vinculantes (por ejemplo, porque se trata de un órgano jurisdiccional que no resuelve en última instancia frente a las valoraciones jurídicas efectuadas en el litigio concreto por el órgano jurisdiccional superior; o porque se

29 de mayo de 1997, KREMZOW, C-299/95, apartado 15, y ROQUETTE FRÈRES, de 22 de octubre de 2002, C-94/00, apartado 25)

74 STJ de 26 de febrero de 2013, C-399/11.

75 Asunto C-617/10.

76 Sentencia MELLONI, cit., apdo. 60; Sentencia AKERBERG, cit., apdo. 29. Sobre el tema, por ejemplo: R. Alonso García, El Juez Nacional en la Encrucijada Europea..., op. cit., pp. 38 y ss.; X. ArzOZ SANTISTEBAN, La tutela de los derechos fundamentales de la Unión Europea por el Tribunal Constitucional, INAP, Madrid, 2015, pp. 31 y ss.; o J.I. Ugartemendia y S. Ripol Carulla, El Tribunal Constitucional en la encrucijada europea de los derechos fundamentales. Un análisis a partir del asunto Melloni y sus implicaciones, IVAP, Oñate, 2016 (espec. punto 3.3 del cap. III). 
trata de la jurisprudencia constitucional). Esta eficacia solapante o desplazadora que ejercen los Derechos Fundamentales de la UE sobre los estándares iusfundamentales nacionales que los contradigan puede ser «impuesta» por el Juez nacional a través del recurso a la cuestión prejudicial ante el TJ.

El órgano jurisdiccional nacional encargado de aplicar el Derecho de la Unión - y los Derechos Fundamentales de la Unión Europea- en el caso concreto que le compete - por ejemplo, en una relación horizontal o entre particulares-analiza y valora si una resolución jurisdiccional nacional previa en materia de Derechos Fundamentales, que de alguna manera le vincula para la resolución del litigio, es o no compatible con el Derecho de la Unión. Surgida la duda de incompatibilidad de estándares, plantearía la remisión prejudicial de interpretación, la cual versaría sobre el Derecho Fundamental de la Carta con el que le parece que podría ser incompatible la resolución jurisdiccional nacional previa que le vincula para poder resolver el caso. Esto es, tenemos, por una parte, una norma europea que reconoce un Derecho Fundamental, básica para resolver el caso, y por otra, una resolución jurisdiccional nacional que vincula al Juez nacional, la cual, según cómo se interprete la norma europea, podría ser o llevar a tomar una decisión contraria al Derecho de la Unión. La consecuencia de este «control», activado con el planteamiento de la prejudicial, se concretaría, en su caso, en no tener en cuenta la resolución jurisdiccional nacional vinculante que, con la ayuda de la sentencia prejudicial del TJ, se mostrase contraria o incompatible con el ordenamiento de la $\mathrm{UE}^{77}$.

Vamos a terminar señalando un ejemplo, referido además a un tema de no discriminación que se ha apuntado con anterioridad. Se trata del asunto F.J. Rosado Santana $(2011)^{78}$, el cual tiene por objeto una petición de decisión prejudicial planteada, con arreglo al artículo 267 FUE, por el Juzgado de lo Contencioso-Administrativo n. ${ }^{\circ} 12$ de Sevilla, en relación a la Directiva 1999/70, dirigida a aplicar el Acuerdo Marco sobre el trabajo de duración determinada. Esta normativa, como ya se ha indicado con antelación, establece un principio de no discriminación que prohíbe tratar a los trabajadores con un contrato de duración determinada de una manera menos favorable que a los trabajadores fijos, a menos que se justifique un trato diferente por razones objetivas. El hecho es que la Administración autonómica andaluza publicó en 2009 una orden mediante la que se convocaban pruebas selectivas por el sistema de promoción interna para los funcionarios de carrera pertenecientes a la misma. Entre los requisitos para concursar en dichas pruebas se encontraba el de poseer una antigüedad de diez años como funcionario de carrera en un determinado grupo. El Sr. Rosado terminará por acudir a los Tribunales al considerar que la Administración andaluza

77 Permítaseme señalar al respecto, para más detalles, mi trabajo titulado: «El control de comunitariedad de las resoluciones jurisdiccionales y el límite de la identidad constitucional», REDE, 59, 2016, pp. 13-43.

78 F.J. ROSADO SANTANA, de 8 de septiembre de 2011, C-177/10. 
infringió el principio de no discriminación del Acuerdo Marco al no computársele los períodos de servicios prestados como funcionario interino (de 1989 a 2005) a efectos de calcular la mencionada y requerida antigüedad de diez años.

Centrándonos ahora en lo que concierne a nuestro tema, hay que señalar que el Juzgado de Sevilla preguntó en su Auto de remisión prejudicial acerca de las repercusiones de determinados autos del Tribunal Constitucional según los cuales un tratamiento diferenciado entre los funcionarios de carrera y los de empleo interino con las mismas funciones era constitucional (si bien, señalando, asimismo, el carácter parcialmente contradictorio de estos pronunciamientos con otras sentencias dictadas por el propio Tribunal Constitucional), apareciendo asî una especie de «control judicial difuso» de comunitariedad sobre la jurisprudencia constitucional previa relativa a la materia ${ }^{79}$.

La respuesta del Tribunal de Justicia será terminante: «en el supuesto de que un tribunal nacional, incluido un tribunal constitucional, excluyera la aplicación de la Directiva 1999/70 y del Acuerdo marco al personal de la función pública de un Estado o permitiera diferencias de trato entre los funcionarios interinos y los funcionarios de carrera a falta de razones objetivas, en el sentido de la cláusula 4, apartado 1 , de dicho Acuerdo marco, procederá declarar que tal jurisprudencia va en contra de lo dispuesto en estas normas del Derecho de la Unión e incumple las obligaciones que incumben a las autoridades judiciales de los Estados miembros, en el marco de sus competencias, de garantizar la protección jurídica que de las disposiciones de dicho Derecho se desprende para los justiciables y de garantizar su pleno efecto» ${ }^{80}$.

$$
* * *
$$

TITLE: The binding effectiveness of the Charter of Fundamental Rights of the European Union in relationships between individuals

AвSTRACT: The main purpose of this paper is to analyze the binding effectiveness of the Charter of Fundamental Rights of the European Union in relationships between individuals. After explaining briefly

79 De forma concreta, las dos primeras de las cinco prejudiciales remitidas planteaban lo siguiente: «(1) Si [la] Directiva [1999/70] debe interpretarse en el sentido de que, dado el caso de que un Tribunal Constitucional de un país miembro de la Unión [Europea] se hubiese pronunciado entendiendo que establecer derechos diferenciados para los funcionarios de empleo y los de carrera del mismo pudiera no resultar contrario a su Constitución, ello necesariamente habría de implicar una exclusión de la aplicabilidad de la referida norma comunitaria en el ámbito de su Función Pública. (2) Si dicha Directiva debe interpretarse en el sentido de que se opone a que un Órgano Jurisdiccional nacional realice una interpretación de los principios de Igualdad de Trato y de no Discriminación en forma que excluya genéricamente de su ámbito la equiparación entre funcionarios de empleo y de carrera».

80 Sobre el tema, por ejemplo, D. ORdóñez Solís, «Empleados públicos, Administraciones Españolas y Jurisprudencia Europea», Actualidad Administrativa, 3, 2012, pp. 2 y ss.; así como también: «Empleo público y jurisprudencia europea: los efectos innovadores en el estatuto del empleado público en España», Unión Europea Aranzadi, 10, 2013, pp. 25 y ss., espec. 51 y ss. Para más ejemplos similares a éste, vid. J.I. UGARTEMENDiA, «El control de comunitariedad de las resoluciones jurisdiccionales...», op. cit., pp. 17 y ss. y 25 y ss. 
its binding capacity in relation to public authorities (vertical efficacy), either in the Union or in the Member States (when applying Union law), the article focuses on the description of the various positions and arguments about the inter privatos effectiveness of the Charter, that is, its ability to bind or constrain (directly or indirectly) individuals (borizontal effectiveness). In that respect, these lines also aim at one of the main issues the Court's case-law is currently facing in this area: whether the connection of a Charter right with a Directive, or its realization in it, strengthens its horizontal binding effectiveness (knowing that, by definition, these rights lack of efficacy in the relationships between individuals), or its invocability, an issue that is being raised in relation to the Charter's rights of equality (particularly, non-discrimination) and of solidarity.

RESUMEN: La finalidad principal de este trabajo es analizar la eficacia vinculante de la Carta de Derechos Fundamentales de la Unión Europea en las relaciones entre particulares. Una vez apuntada brevemente la capacidad vinculante de la misma en relación al poder público (eficacia vertical), sea de la Unión o de los Estados miembros (cuando aplican Derecho de la Unión), el artículo se centra en la descripción de las diversas posiciones y argumentos en torno a la eficacia inter privatos de la Carta, esto es, a su capacidad para vincular (directa o indirectamente) a los particulares (eficacia horizontal). Puestos a ello, estas líneas se adentran, asimismo, en señalar una de las principales cuestiones a las que se enfrenta en la actualidad la jurisprudencia del Tribunal de Justicia en esta materia. Esto es, si la conexión de un derecho de la Carta con una Directiva, o su concreción en la misma, viene a fortalecer su eficacia vinculante horizontal (sabiendo que, por definición, éstas carecen de tal eficacia en las relaciones entre particulares) o invocabilidad, una cuestión que se está planteando en relación con los derechos de igualdad (particularmente, con la no discriminación) y con los derechos de solidaridad de la Carta.

KEY WORDS: Fundamental Rights of the European Union, drittwirkung or Binding Effectiveness of the Charter on Inter Privatos Relations (horizontal effect), effects of the Charter in connection with the Directives, principle of non discrimination in relations between individuals.

Palabras clave: Derechos Fundamentales de la Unión Europea, eficacia vinculante de la Carta en las relaciones inter privatos (eficacia horizontal), efectos de la Carta por su conexión con las Directivas, principio de no discriminación en las relaciones entre particulares.

FECHA DE RECEPCión: 15.12.2016 FeCHA DE ACEPTACión: 01.02.2017 